\title{
SOME STUDIES ON CALCIUM AND PHOSPHORUS CONCENTRATION IN THE SMALL AND LARGE INTESTINES OF CHILDREN
}

BY

\author{
ANGELIA M. COURTNEY, B.A. \\ (From Sub-Department of Pædiatrics of the University of Toronto, and the \\ Hospital for Sick Children, Toronto.)
}

This study was undertaken in the hope of obtaining some knowledge of excretion and absorption of calcium and phosphorus in the intestinal tract beyond that afforded by balance experiments and examination of the fæces.

The material investigated was obtained from thirty-four post-mortem examinations of the intestinal tract of children. It was out of the question to make much selection of cases for study. They were obtained over a period of thirteen months and represent as regards the intestinal tract both normal and pathological conditions. According to a classification based on the clinical and post-mortem reports, in twenty-one cases intestinal conditions were primarily normal ; in fourteen definitely pathological. In thirteen cases signs of active rickets were reported, eight in the group showing acute intestinal symptoms. The group normal as to intestines included cases of decomposition, prematurity, broncho-pneumonia, erysipelas, nephritis, cellulitis, encephalitis, meningitis, hydrocephalus, scurvy, hæmorrhagic disease of the new-born and cerebral hæmorrhage following. injury. The gastro-intestinal cases were described as acute intestinal intoxication, fermentative diarrhœa, one pyloric stenosis, one intestinal obstruction. The ages ranged from twelve days to four and three-quarter years, with the larger number between two months and one year.

The post-mortem examinations took place from two to twenty-four hours after death, the greater number within twelve hours. The material was, with few exceptions, used immediately after removal from the intestines. When this was not the case, it was kept covered in an ice-box and used as soon as possible. When there was sufficient material and it could be used at once, the moist material was made into an emulsion and a portion was used for hydrogen-ion determination. The remainder was dried to constant weight on a steam-bath in order to afford a basis for calculating the values as percentage of total solids. Calcium and phosphorus were determined in the dried material by standard gravimetric methods. When the material could not be used at once, or there was little obtained, the reaction was tested in the moist substance by the use of litmus paper and all was dried to constant weight to be used for the calcium and phosphorus estimations. When material permitted, chloride was estimated in the dried substance. 
With three exceptions the intestinal contents were collected in two portions, all the material between the pylorus and the ileo-colic valve, and all that after the ileo-colic valve. In three cases only was it possible to collect separately the contents before the ileum and the contents of the ileum. A strictly quantitative removal of the contents was not attempted owing to the difficulty encountered in obtaining the material without admixture of blood. Accordingly the values reported represent concentrations, not the absolute amounts present. The total values would, however, have no significance here since no relation to the food intake was known.

Table 1 gives the average values for calcium and phosphorus concentration in the small and in the large intestine for all the cases. These cases are in addition classified in three groups, those with and those without intestinal symptoms, and those showing signs of rickets whether in the intestinal or in the non-intestinal group, and the averages for these groups are given in Table 1. Table 1 also includes the ratio of the concentration in the large to that in the small intestine of both calcium and phosphorus for each of the groups.

TABLE 1.

Average concextration of Calcium and pilosphorus in SMall axd Large intestines IN GRAMMES PER GRAMME OF TOTAL SOLIDS.

\begin{tabular}{|c|c|c|c|c|c|c|c|c|c|c|}
\hline & \multicolumn{5}{|c|}{$\mathrm{CaO}$} & \multicolumn{5}{|c|}{$\mathrm{P}_{2} \mathrm{O}_{5}$} \\
\hline & \multicolumn{2}{|c|}{$\begin{array}{l}\text { 1. Small } \\
\text { intest. }\end{array}$} & \multicolumn{2}{|c|}{$\begin{array}{l}\text { 2. Large } \\
\text { intest. }\end{array}$} & \multirow[t]{2}{*}{$\begin{array}{l}\text { Ratio } \\
1: 2 .\end{array}$} & \multicolumn{2}{|c|}{$\begin{array}{l}\text { 1. Small } \\
\text { intest. }\end{array}$} & \multicolumn{2}{|c|}{$\begin{array}{l}\text { 2. Large } \\
\text { intest. }\end{array}$} & $\begin{array}{l}\text { Ratio } \\
1: 2 .\end{array}$ \\
\hline & $\begin{array}{l}\text { No. } \\
\text { Cases }\end{array}$ & Aver. & $\begin{array}{l}\text { No. } \\
\text { Cases }\end{array}$ & Aver. & & $\begin{array}{l}\text { No. } \\
\text { Cases }\end{array}$ & Aver. & $\begin{array}{l}\text { No. } \\
\text { Cases }\end{array}$ & Aver. & \\
\hline Total number & 34 & .0149 & 30 & .0371 & $2 \cdot 5$ & 32 & .0293 & 23 & .0452 & $1 \cdot 5$ \\
\hline Not intestinal & 20 & .0183 & 19 & .0466 & $2 \cdot 5$ & 19 & .0315 & 15 & .0544 & $1 \cdot 7$ \\
\hline Intestinal & 14 & .0101 & 11 & .0205 & $2 \cdot 0$ & 13 & .0261 & 8 & .0279 & $1 \cdot 1$ \\
\hline Rachitic & 12 & .0135 & 11 & .0324 & $2 \cdot 4$ & 11 & .0268 & 8 & .0510 & $1 \cdot 9$ \\
\hline
\end{tabular}

The following points are shown in this table :-

1. In all three groups calcium concentration in the large intestine is markedly greater than in the small.

2. Phosphorus concentration is definitely greater in the large intestine than in the small except in the group with intestinal symptoms.

3. The ratio of concentration in the large to that in the small intestine is much greater for calcium than for phosphorus.

4. With the intestinal cases the ratio of both calcium and phosphorus concentration in the large to that in the small intestines is much smaller than with the cases without intestinal symptoms. In other words the concentration in the large intestine more nearly resembles that in the small in the abnormal intestinal conditions, in most of which there was increased peristalsis. 
5. In the rachitic group the ratio of phosphorus concentration in the large to that in the small intestine is greater than the average for all the cases. This difference is not sufficiently marked to afford a basis for discussion, particularly as the stage of healing of the rickets was not known in any of the cases.

Table 2 gives averages of the same values used in Table 1 but here classified according to the reaction of the material. For this purpose hydrogen-ion concentration more acid than $\mathrm{pH} 6 \cdot 8$ were considered acid, those from $\mathrm{pH} 6 \cdot 8$ through $\mathrm{pH} 7.0$ neutral, and those more alkaline than $\mathrm{pH} 7.0$ alkaline. This more or less arbitrary basis was fixed upon as giving the best agreement with the litmus paper tests. This table calls for little comment. The values for the acid and alkaline groups show the expected relationship, greater concentrations of calcium and phosphorus corresponding to alkaline reactions. The values for the neutral group are of less significance as the group was so small.

Only general conclusions can be drawn from these averages, for the individual values making up each average show a fairly wide range. There were, however, only two exceptions to the rule that calcium concentration is greater in the large than in the small intestine. In these two, total ash and phosphorus concentration also were less in the large intestine. In six instances the phosphorus concentration was less in the large than in the small intestine, though in all these the concentration of calcium was as usual greater in the large. In all but one of these the contents of the large intestine were distinctly acid, in four of them more acid than in the corresponding small intestine. As inorganic phosphorus was not estimated by itself no assumption can be made as to what proportion of the calcium present was bound to phosphorus.

TABLE 2.

Average concentration of Calcium and phosphores in syall axd Large intestines IN GRAMMES PER GRAMME OF TOTAL SOLIDS.

$\mathrm{CaO}$

\begin{tabular}{|c|c|c|c|c|c|c|c|}
\hline & & \multicolumn{3}{|c|}{ Small intestine } & \multicolumn{3}{|c|}{ Large intestine } \\
\hline & & $\begin{array}{l}\text { No. } \\
\text { cases }\end{array}$ & Average & Range & $\begin{array}{l}\text { No. } \\
\text { cases }\end{array}$ & Average & Range \\
\hline Total number & $\ldots$ & 34 & .0149 & $.0020-.0515$ & 30 & .0371 & $.0056-\cdot 1463$ \\
\hline Acid reaction & $\ldots$ & 31 & .0135 & $.0020-.0298$ & 18 & .0300 & $.0056-.0781$ \\
\hline Neutral ,, & $\ldots$ & 1 & .0188 & & 4 & .0256 & $.0083-.0438$ \\
\hline Alkaline , & $\cdots$ & 2 & .0346 & $.0176-.0515$ & 8 & .0587 & $\cdot 0100-\cdot 1463$ \\
\hline \multicolumn{8}{|c|}{$\mathrm{P}_{2} \mathrm{O}_{5}$} \\
\hline Total number & $\ldots$ & 32 & .0293 & $.0069-.0486$ & 23 & .0482 & $\cdot 0158-\cdot 1384$ \\
\hline Acid reaction & $\ldots$ & 29 & .0289 & $.0069-.0449$ & 13 & .0388 & $\cdot 0158-\cdot 1034$ \\
\hline Neutral , & $\ldots$ & 1 & .0237 & & 3 & .0408 & $.0318-.0491$ \\
\hline Alka.ine ," & $\cdots$ & 2 & $\cdot 0365$ & $.0244-.0486$ & 7 & $\cdot 0588$ & $\cdot 0270-\cdot 1384$ \\
\hline
\end{tabular}


Table 3 gives the average chloride values for the small number of estimations made, arranged in groups corresponding to those in Table 1. The number making the averages is too small to allow great importance to be attached to them. They are included because of the strikingly higher concentration of chlorides in the rachitic cases than in the others. This might be expected if the rickets happened to be in the healing stage with most of these cases, since it has been observed that in rats with healing rickets the contents of the large intestine are more watery than those of normal or actively rachitic rats ${ }^{1}$, and it is also known that the sodium chloride content of fæces is increased with the water content.

TABLE 3.

Average concentration of Chlorides in Shall aNd LARge intestines in grammes per GRAMME OF TOTAL SOLIDS.

\begin{tabular}{|c|c|c|c|c|c|c|c|}
\hline & & \multicolumn{3}{|c|}{ Small intestine } & \multicolumn{3}{|c|}{ Large intestine } \\
\hline & & $\begin{array}{l}\text { No. } \\
\text { Cases }\end{array}$ & Average & Range & $\begin{array}{l}\text { No. } \\
\text { Cases }\end{array}$ & Average & Range \\
\hline Total number & $\ldots$ & 17 & .0218 & $.0107-.0407$ & 7 & .0107 & $.0031-.0299$ \\
\hline Not intestinal & $\ldots$ & 12 & .0221 & $.0113-.0407$ & 6 & .0103 & $.0031-.0299$ \\
\hline Intestinal $\quad \ldots$ & $\ldots$ & 5 & .0212 & $.0107-.0357$ & 1 & .0103 & \\
\hline Rachitic ... & $\ldots$ & 7 & .0300 & $.0113-.0407$ & 2 & .0208 & $.0116-.0299$ \\
\hline
\end{tabular}

The data obtained from this investigation are not extensive enough to justify drawing any definite conclusions as to absorption and excretion relations of calcium and phosphorus in the intestinal tract. However, since the ratio of phosphorus concentration in the large intestine to that in the small is distinctly less than the corresponding calcium ratio, it can fairly be concluded that these two constituents are not entirely interdependent in regard to absorption and excretion. This observation is in agreement with the findings in a study of the intestinal contents of rats recently made in this laboratory. ${ }^{1}$

This difference between calcium and phosphorus in the relation of their concentration in the large and the small intestine must be due either to greater increase in excretion of calcium than of phosphorus in passing into the large intestine, or to relatively less absorption of calcium than of phosphorus. This greater excretion or less absorption of calcium in the large intestine in comparison with phosphorus is brought out in another way. Inorganic phosphorus values were not obtained, hence the proportion of calcium bound as phosphate cannot be calculated even in approximate terms. However, if only about half the total phosphorus present can be regarded as inorganic phosphorus, as we found to be the case in the study of rats just referred to, then Table 1 shows that in all children investigated calcium must have been present in the large intestine in considerable proportion in some other combination than as phosphate. In the small intestine this excess of calcium was not present. 


\section{Conclusions.}

The results here reported indicate that there was greater excretion or less absorption of calcium than of phosphorus in the large intestine in all the children studied. It also appears probable that the calcium concentration in the large intestine was due in considerable proportion to calcium not bound to phosphorus.

In the children with abnormal intestinal conditions there was much less difference between the large and the small intestine in both calcium and phosphorus concentration than in those without intestinal symptoms.

Thanks are due the Pathological Department of the Hospital for Sick Children, Toronto, for assistance rendered in obtaining the material for this study.

\section{REFERENCES.}

1. Courtney, A. MI., Tisdall, F. F. \& Brown, A., C'an. Med. Assoc. J., MIontreal, 1928, XIX, $5 \dot{59}$ - 